\title{
Short communication: Development of the first follicular wave dominant follicle on the ovary ipsilateral to the corpus luteum is associated with decreased conception rate in dairy cattle
}

\author{
R. Miura, ${ }^{*} †$ S. Haneda, $†$ M. Kayano, $\ddagger$ and M. Matsui ${ }^{1}$ \\ *The United Graduate School of Veterinary Sciences, Gifu University, Yanagido, Gifu, 501-1193, Japan \\ †Department of Clinical Veterinary Science, and \\ ¥Graduate School of Animal and Food Hygiene, Obihiro University of Agriculture and Veterinary Medicine, Inada, Obihiro, 080-8555, Japan
}

\begin{abstract}
In this study, we examined the effect of the locations of the first-wave dominant follicle (DF) and corpus luteum (CL) on fertility. In total, 350 artificial insemination (AI) procedures were conducted (lactating dairy cows: $\mathrm{n}=238$, dairy heifers: $\mathrm{n}=112$ ). Ovulation was confirmed $24 \mathrm{~h}$ after AI. The locations of the first-wave $\mathrm{DF}$ and CL were examined 5 to $9 \mathrm{~d}$ after AI using rectal palpation or transrectal ultrasonography. Lactating dairy cows and dairy heifers were divided into 2 groups: (1) the ipsilateral group (IG), in which the DF was ipsilateral to the CL; and (2) the contralateral group (CG), in which the DF was contralateral to the CL. Pregnancy was diagnosed using transrectal ultrasonography $40 \mathrm{~d}$ after AI. Conception rates were $54.0 \%$ in all cattle: $48.9 \%$ in lactating dairy cows, and $58.9 \%$ in dairy heifers. The incidence of the first-wave DF location did not differ between IG and CG (all cattle: 184 vs. 166 ; lactating cows: 129 vs. 109 ; heifers: 55 vs. 57 for IG vs. CG). Conception rates were lower in IG than in CG (all cattle: 40.2 vs. $69.3 \%$; lactating dairy cows: 38.0 vs. $67.0 \%$; dairy heifers: 45.5 vs. $73.7 \%$, for IG vs. $\mathrm{CG})$. Conception rate was not affected by season or live weight in heifers and lactating cows. In addition, days in milk at AI, milk production, body condition score, and parity did not affect conception in lactating cows. In summary, development of the first-wave DF in the ovary ipsilateral to the CL was associated with reduced conception rates in both lactating cows and heifers.
\end{abstract}

Key words: first-wave dominant follicle, corpus luteum, conception rate

\section{Short Communication}

In cattle, 2 or 3 follicular waves occur during the estrous cycle (Sirois and Fortune, 1988). The first fol-

Received May 19, 2014.

Accepted October 9, 2014.

${ }^{1}$ Corresponding author: mmatsui@obihiro.ac.jp licular wave emerges soon after estrus, and the firstwave dominant follicle (DF) undergoes atresia during d 8 to 10 of the estrous cycle; therefore, most first-wave DF are not ovulated (Ginther et al., 1989a).

The dynamics of DF growth and the hormonal milieu during first-wave development have been well studied (Adams et al., 2008). However, the influence of the firstwave DF on fertility (conception rate) in cattle remains uninvestigated. Furthermore, the first-wave DF can develop contralateral or ipsilateral to the corpus luteum (CL). In a previous study, the relative locations of the first-wave DF and CL were studied, and the number of follicular waves with the DF and CL ipsilateral or contralateral to the ovaries did not vary during the first wave (Ginther et al., 1989b). However, the locational effect of the first-wave DF contralateral or ipsilateral to the CL on fertility remains unevaluated.

During the follicular phase, the concentration of estradiol (E2) in the oviduct ipsilateral to the preovulatory follicle is higher than that in the oviduct contralateral to the preovulatory follicle (Wijayagunawardane et al., 1998). The first-wave DF produces E2 (Badinga et al., 1992), and the plasma concentration of E2 increases during the early stage of the estrous cycle (Savio et al., 1993). These observations indicate that the concentration of E2 in the oviduct or uterine horn may be higher when they are ipsilateral than when they are contralateral to the first-wave DF, which may influence the condition of the oviduct or uterine horn for embryonic development. Thus, we hypothesize that fertility would differ if the first-wave DF is or is not ipsilateral to the CL on the same side as the oviduct and uterus containing the embryo. The purpose of our study was to compare conception rates between first-wave DF that are ipsilateral and contralateral to the CL in ovaries of lactating dairy cows and dairy heifers.

Postpartum lactating Holstein cows $(\mathrm{n}=153)$ and heifers $(\mathrm{n}=75)$ at the Field Science Center of Obihiro University in Hokkaido, northeast Japan, were used. The trial was conducted from March 2008 to September 2013. Cattle underwent regular estrous cycles and were 
clinically healthy during the breeding period. Cattle experiencing reproductive or metabolic diseases were excluded. In total, 350 AI procedures were performed, including $238 \mathrm{AI}$ in lactating dairy cows (postpartum day of AI: $119.8 \pm 5.2$, parity: $2.2 \pm 0.1$, milk production: $33.9 \pm 0.5 \mathrm{~kg} / \mathrm{d}$, BCS: $2.91 \pm 0.02$, live weight: $637.4 \pm 4.6 \mathrm{~kg}$; means $\pm \mathrm{SEM}$ ) and $112 \mathrm{AI}$ in dairy heifers (age: $14.2 \pm 0.3 \mathrm{mo}$, live weight: $440.6 \pm 5.0 \mathrm{~kg}$; means \pm SEM). The cows were kept in a freestall barn under the normal management program of the Field Science Center of Obihiro University, and they were fed a TMR diet consisting of corn silage, grass silage, soybean meal, corn grain, and concentrate, with free access to water. All cows were milked twice daily on a parallel parlor. Artificial inseminations were begun in lactating cows $60 \mathrm{~d}$ after parturition and heifers were inseminated if their BW was $>350 \mathrm{~kg}$.

Cows and heifers were inseminated after estrus was detected by visual observation, examination of tail paint, and rectal palpation to confirm the preovulatory follicle and regressed CL. Ovulation was confirmed 24 $\mathrm{h}$ after insemination using rectal palpation or transrectal ultrasonography. If a cow did not ovulate, it was reinseminated, and ovulation was confirmed $24 \mathrm{~h}$ after insemination. If a cow did not ovulate after the second insemination, it was excluded from the trial. After ovulation was confirmed, we checked the CL and first-wave DF (diameter $>1.2 \mathrm{~cm}$ ) 5 or $6 \mathrm{~d}$ after AI using transrectal ultrasonography. If the largest follicle was not $>1.2 \mathrm{~cm}$, the ovary was re-examined by rectal palpation 2 to $3 \mathrm{~d}$ later, and the largest follicle was defined as the first-wave DF. If growth of the largest follicle was not evident, the animal was excluded from the study. In addition, if an animal had co-dominant follicles, it was excluded it from the study. The location of the first-wave DF in the ovary was confirmed at that time to be ipsilateral (ipsilateral group: IG) or contralateral (contralateral group: CG) to the CL. Pregnancy was diagnosed by transrectal ultrasonography at $40 \mathrm{~d}$ after AI. If estrus was detected before 40 $\mathrm{d}$, we concluded that pregnancy had not occurred and reinseminated the cattle.

Two statistical analyses were performed: the chisquared test and binary logistic regression. In all cattle, conception rates between the IG and CG were analyzed by chi-squared test. For more detailed analysis, binary logistic regression was applied to heifers and lactating cows, respectively. In both analyses of logistic regression, pregnancy status was analyzed as a dependent variable. The common independent variable was the location of the first-wave DF and CL (IG, CG). In heifers, additional independent variables for the logistic regression model were season (warm: June-September, cool: October-March) and live weight $(<441 \mathrm{~kg}, \geq 441$ $\mathrm{kg})$. In lactating cows, season, DIM at AI ( $\leq 120 \mathrm{~d},>120$ d), milk production $(<34 \mathrm{~kg}, \geq 34 \mathrm{~kg})$, parity $(1,2, \geq 3)$, BCS $(<3, \geq 3)$, and live weight $(<637 \mathrm{~kg}, \geq 637 \mathrm{~kg})$ were incorporated into the logistic regression model. Milk production, BCS, and live weight were measured every month on this farm. We used the values obtained in the month when the animal received AI. Milk production, BCS, and live weight showed a normal distribution in this study, so we classified each independent variable into 2 groups by the mean. Statistical significance was declared for $P<0.05$. All analyses were carried out using R software version 2.14.0 for Mac OS X (http:// cran.md.tsukuba.ac.jp/bin/macosx/).

The incidence of the first-wave DF location in the ovary ipsilateral and contralateral to the CL did not differ significantly in all cattle (IG vs. CG, 184 vs. 166), lactating dairy cows (IG vs. CG, 129 vs. 109), or dairy heifers (IG vs. CG, 55 vs. 57). Conception rates were $54.0 \%$ in all cattle, $48.9 \%$ in lactating dairy cows, and $58.9 \%$ in dairy heifers.

The IG group had a significantly lower conception rate $(40.2 \%)$ than the CG group $(69.3 \%)$ in all cattle. The results were the same in lactating dairy cows and dairy heifers (lactating dairy cows: 38.0 vs. $67.0 \%$, dairy heifers: 45.5 vs. $73.7 \%$ for IG vs. CG; Figure 1). In dairy heifers, conception rate was not affected by season or live weight, and in lactating dairy cows, conception rates were not affected by season, DIM at AI, milk production, BCS, parity, or live weight. Table 1 is the regression table for the logistic regression model. These results were same when we added cows and heifers as a random variable in the logistic regression model (lactating dairy cows; odds ratio $=3.56: P<0.001$; dairy heifers; odds ratio $=3.08: P<0.01$ ).

In a previous study, relative locations of the first-wave DF and CL were studied, and the numbers of follicular wave with the DF and CL ipsilateral or contralateral to the ovary were not different in the first wave (Ginther et al., 1989b), as found in the present study. We compared conception rates between the first-wave DF in the ovary ipsilateral and contralateral to the CL after AI in cattle. In both lactating dairy cows and dairy heifers, conception rates were lower when the first-wave DF was located ipsilateral to the CL. To the best of our knowledge, this was the first report showing that the first-wave DF in the ovary ipsilateral to the CL after AI is associated with reduced conception rate in cattle. From the results of logistic regression, only the locational effect (IG or CG) affected conception rates in both lactating dairy cows and dairy heifers. On the other hand, season, DIM at AI, milk production, BCS, parity, and live weight did not affect conception rates in both groups. Based on these results, the lower conception rate in IG, which was observed in both lactating 
Table 1. Regression table of the logistic regression model for factors affecting conception rate in dairy lactating cows and heifers

\begin{tabular}{lcccc}
\hline Group & Coefficient & Odds ratio & $95 \% \mathrm{CI}$ & $P$-value \\
\hline Lactating dairy cows & -1.31 & & & \\
$\quad$ Intercept & 1.20 & 3.31 & $1.94-5.65$ & $<0.001$ \\
$\quad$ Location & & & & \\
Dairy heifers & -1.69 & & & \\
$\quad$ Intercept & 1.12 & 3.08 & $1.40-6.74$ & $<0.01$ \\
Location &
\end{tabular}

${ }^{1}$ Location $=$ the location of the first-wave dominant follicle in the ovary was confirmed at that time to be ipsilateral or contralateral to the corpus luteum.

dairy cows and dairy heifers, might not be influenced by lactation. This phenomenon was probably caused by an innate physiological mechanism in cattle.

However, the mechanism of lower fertility when the first-wave DF is ipsilateral to the CL remains unclear. The endometrium of the uterine horn that is located on the same side of the ovary as CL has a higher progesterone (P4) concentration compared with the endometrium in the opposite uterine horn (Cerbito et al., 1994). In addition, the concentration of $\mathrm{E} 2$ in the oviduct ipsilateral to the preovulatory follicle is higher than that contralateral to the preovulatory follicle in bovine (Wijayagunawardane et al., 1998). These results indicate a strong local interaction between the uterine horn and the same-side ovary. The first-wave DF pro-

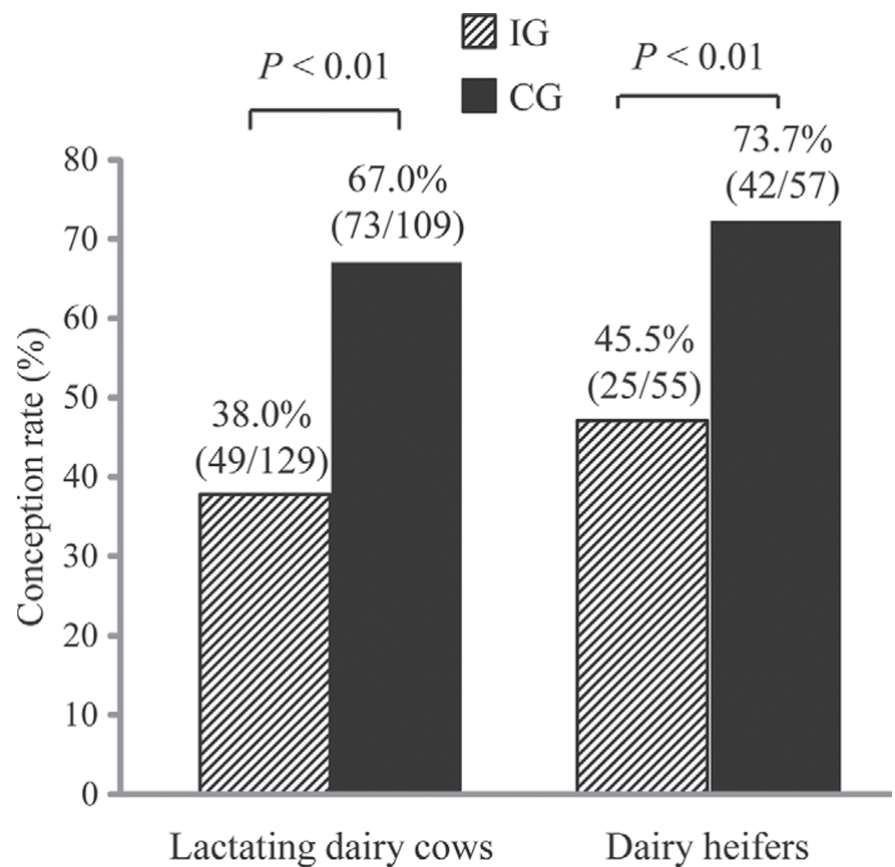

Figure 1. Conception rates in the ipsilateral group (IG) and contralateral group (CG). Conception rates were different $(P<0.01)$ between IG and CG in both lactating dairy cows and dairy heifers. Ipsilateral (contralateral) $=$ first-wave dominant follicle was ipsilateral (contralateral) to the corpus luteum. duces and secretes E2 during follicular development in cows (Savio et al., 1993); therefore, it is possible that the concentration of E2 in the oviduct or uterine horn ipsilateral to the first-wave DF was higher than that contralateral to the first-wave DF. Estradiol increases mRNA expression of estrogen receptor $\alpha$ and P4 receptor in bovine oviduct epithelial cells in vitro (Ulbrich et al., 2003). In addition, E2 increases estrogen receptors and $\mathrm{P} 4$ receptors in bovine endometrial stromal cells in vitro (Xiao and Goff, 1999). These results indicate that E2 regulates the expression of steroid receptors of the oviduct and uterus. Therefore, we hypothesize that E2 secreted from the first-wave DF may have locally affected the same side of the uterine horn or oviduct and affected the function of the reproductive tract, which was associated with decreased fertility in IG. Another possibility exists for a negative role of $\mathrm{E} 2$ on fertility. If E2 released from the DF has negative effects on ipsilateral CL formation, P4 synthetic capacity or the lifespan of the CL in the DF located ipsilateral to the CL may result in low fertility. To investigate the mechanism of low fertility caused by the first-wave DF ipsilateral to CL, further research is required to study the effects of E2 on functions of the oviduct, uterus, and CL during the early luteal phase.

In previous studies, human chorionic gonadotropin (hCG) treatment after AI was administered to improve conception rate in dairy cattle (Nascimento et al., 2013). However, the effects of hCG administration on fertility are not consistent between studies (Santos et al., 2001; Hanlon et al., 2005), and these studies did not address the locational effect of the first-wave DF on conception rate after hCG treatment. Results from the present study suggest that the first-wave DF developing ipsilateral to CL might have a negative local influence on fertility. Because ovulation of the first-wave DF in IG by hCG treatment could eliminate the detrimental effects on fertility, conception rate may increase. Further research is needed to verify the locational effect of the first-wave DF on fertility after hCG treatment. In conclusion, the present study demonstrated that the first-wave DF located ipsilateral to the CL in the ovary 
was associated with reduced conception rates in both lactating dairy cows and dairy heifers.

\section{ACKNOWLEDGMENTS}

This study was supported by the Grant-in-Aid for Scientific Research (26660234) from the Japan Society for the Promotion of Science (JSPS).

\section{REFERENCES}

Adams, G. P., R. Jaiswal, J. Singh, and P. Malhi. 2008. Progress in understanding ovarian follicular dynamics in cattle. Theriogenology $\quad 69: 72-80$

Badinga, L., M. A. Driancourt, J. D. Savio, D. Wolfenson, M. Drost, R. L. De La Sota, and W. W. Thatcher. 1992. Endocrine and ovarian responses associated with the first-wave dominant follicle in cattle. Biol. Reprod. 47:871-883.

Cerbito, W. A., A. Miyamoto, C. R. Balagapo Jr., N. G. Natural, K. Miyazawa, and K. Sato. 1994. Prostaglandin E2 levels in uterine tissues and its relationship with uterine and luteal progesterone during the estrous cycle in dairy cows. Theriogenology 42:941950.

Ginther, O. J., J. P. Kastelic, and L. Knopf. 1989b. Intraovarian relationships among dominant and subordinate follicles and the corpus luteum in heifers. Theriogenology 32:787-795.

Ginther, O. J., L. Knopf, and J. P. Kastelic. 1989a. Temporal associations among ovarian events in cattle during oestrous cycles with two and three follicular waves. J. Reprod. Fertil. 87:223-230.
Hanlon, D. W., G. M. Jarratt, P. J. Davidson, A. J. Millar, and V. L. Douglas. 2005. The effect of hCG administration five days after insemination on the first service conception rate of anestrous dairy cows. Theriogenology 63:1938-1945.

Nascimento, A. B., R. W. Bender, A. H. Souza, H. Ayres, R. R. Araujo, J. N. Guenther, R. Sartori, and M. C. Wiltbank. 2013. Effect of treatment with human chorionic gonadotropin on day 5 after timed artificial insemination on fertility of lactating dairy cows. J. Dairy Sci. 96:2873-2882.

Santos, J. E., W. W. Thatcher, L. Pool, and M. W. Overton. 2001. Effect of human chorionic gonadotropin on luteal function and reproductive performance of high-producing lactating Holstein dairy cows. J. Anim. Sci. 79:2881-2894.

Savio, J. D., W. W. Thatcher, L. Badinga, R. L. de la Sota, and D. Wolfenson. 1993. Regulation of dominant follicle turnover during the oestrous cycle in cows. J. Reprod. Fertil. 97:197-203.

Sirois, J., and J. E. Fortune. 1988. Ovarian follicular dynamics during the estrous cycle in heifers monitored by real-time ultrasonography. Biol. Reprod. 39:308-317.

Ulbrich, S. E., A. Kettler, and R. Einspanier. 2003. Expression and localization of estrogen receptor alpha, estrogen receptor beta and progesterone receptor in the bovine oviduct in vivo and in vitro. J. Steroid Biochem. Mol. Biol. 84:279-289.

Wijayagunawardane, M. P., A. Miyamoto, W. A. Cerbito, T. J. Acosta, M. Takagi, and K. Sato. 1998. Local distributions of oviductal estradiol, progesterone, prostaglandins, oxytocin and endothelin-1 in the cyclic cow. Theriogenology 49:607-618.

Xiao, C. W., and A. K. Goff. 1999. Hormonal regulation of oestrogen and progesterone receptors in cultured bovine endometrial cells. J. Reprod. Fertil. 115:101-109. 